\title{
PREMISES AND CONDITIONS FOR THE IMPLEMENTATION OF GOVERNMENT- CERTIFIED E-COMMUNICATION ON THE EXAMPLE OF SELECTED EU COUNTRIES
}

\author{
JACEK BUKO \\ University of Szczecin, Faculty of Management and Economics of Services, POLAND \\ e-mail: jacek.buko@wzieu.pl
}

RECEIVED

ACCEPTED

JEL

CLASSIFICATION

KEYWORDS

ABSTRACT
6 November 2018

3 December 2018

H44, K23, K24, L87

e-communication, e-goverment, IT security

One of the basic conditions for the functioning of the 21 st century society is the use and development of Information and Communication Technologies (ICT). Modern communication mostly takes place in the virtual sphere, so a modern state should adapt its potential to this trend and provide citizens with efficient digital service. The e-goverment services seem to be a particularly important developmental direction in this area. These services are used by the state administration to conduct communication and exchange documents with citizens. A prerequisite for citizens to be able to use these services seamlessly is to ensure effective e-communication by the state. The main purpose of this article is to try to identify the factors that determine the usability and safety of e-communication. The considerations underlined the problems of IT security in case of the substitution of paper documents with electronic documents. Although modern technologies can guarantee a high level of security for all forms of e-communication, the use of them is not free of threats. Moreover, with the development and expansion of the e-services offer, new opportunities for fraud and criminal activity by means of teleinformation appear.

\section{Introduction}

The ability to communicate efficiently brings tangible benefits in social and economic life; moreover, it is one of the determinants of the development of the country and society. Today, this ability is ensured by the use of ICT. The term e-communication is more and more often used in the present language. In the era of information society, it is no longer possible for the public sector to function without the widespread use of this form of communication. 
Comprehensive computerization in public administration is called e-government. According to the European Commission, it relies on the use of ICT in close connection with the necessary organizational change and new skills of public services in order to improve the quality of services provided by the administration. Services offered as part of e-administration are referred to as e-services, and their immanent feature is remote provision via the Internet, fully automated or requiring a small human participation.

The idea of developing electronic administration has been present in the European Union's policy since the early 1990s. The dissemination of e-government is of great importance in the development of the information society. This in turn is one of the priorities in EU policy. Widespread computerization, an introduction of innovations, dissemination of new media and effective use of ICT are to ensure the European Union's competitiveness in the international arena. In the currently implemented Europe 2020 strategy, one of the seven flagship projects is the so-called European Digital Agenda. Its task is to determine the main role that ICT must play in order to make more than $50 \%$ of EU citizens use e-government (European Commission, 2010).

The entry into force in 2016 of the Regulation on electronic identification and trust services for electronic transactions in the internal market (the so-called eIDAS) (Regulation EU..., 2014) of the European Parliament and of the Council of 23 July 2014 on electronic identification and trust services for electronic transactions in the internal market and repealing Directive 1999/93/EC paved the way for creating an efficient digital circulation of official correspondence in EU countries. This regulation norms and at the same time improves the way of authentication and signing of electronic documents. The features of an electronic document authenticated according to the elDAS principles enable it to fulfil the functions that today are assigned to a traditional document. This applies above all to the special evidential value of the document, related to the durability and consistency of the written expression. Appropriately prepared e-communication has not only all the key advantages of written communication, but it is much faster and more accessible, and in general it is much cheaper.

\section{Desirable solutions in the field of institutional service of government-certified e-communication}

In every European Union country, there are from several hundred to even over ten thousand separate e-government websites. In many countries, therefore, attempts have been made to create and implement a government-controlled e-communication platform integrating separate services. This platform, acting as a government-certified gateway to digital services of the state, offers a secure e-box, whose task is to handle and archive digital correspondence between the administration and the citizen, carried out so far in the form of traditional registered mail. E-box is assumed to be the carrier of the e-identity service, thanks to which it is possible to authenticate the user. Such digital authentication guarantees the authenticity and integrity of correspondence and confirms the time of its sending and receipt of the e-document. IT system that supports this type of e-box should in principle automate the existing paper procedures, making the citizen able to quickly and intuitively pursue official matters and retrieve invoices using any computer or mobile device.

Despite the undoubted advantages of the e-communication platform, its popularity in the various EU countries studied is strongly diversified. Assuming a rational evaluation criterion that the minimum measure of the success of implementing such a platform is the use of e-government services via this platform by more than $20 \%$ of the adult population of a given country, one can indicate a group of countries where this success can be considered multiplied. These countries certainly include Estonia, Denmark and the Czech Republic, and to a lesser extent Sweden, Norway and France. In the first three of these countries, over $50 \%$ of the adult population uses the 
e-communication platform. The use of this solution in Germany, Austria, Switzerland, Hungary and Poland is definitely below expectations. ${ }^{1}$

Due to the limited size of this text, it is impossible to present the specifics of each of the solutions applied in individual countries, but generally, it can be concluded that the success factors are primarily the complexity of the offer and the pressure exerted by the government on particular target groups of e-communication users. An extreme case is Estonia, where the administration for internal purposes of the country operates completely without using paper, and citizens have only electronic identity cards (https://e-estonia.com, 2018). Denmark, the second largest European country with the highest intensity of e-administration, obliges every citizen over 15 years of age to have a government - certified e-box (https://digst.dk, 2018). Both countries are at the same time the only examples of the administrative coercion of individuals to use e-communication with the administration. Of course, in all studied countries, e-communication must be used by the state administration itself. At this point, it should be stressed that the factor strongly stimulating the use of e-administration by individuals is the mandatory participation in digital document circulation by commercial companies. An important observation is also that the number of entities allowed by the state to integrate e-government websites is unaffected by the development of e-communication. For example, a government-run De-Mail e-communication service in Germany can be provided by any private operator who receives government accreditation. Until now, this service was primarily provided by companies from the ICT industry, including Deutsche Telekom AG, T-Systems and United Internet. The German public post, which is also developing its E-Postbrief system in parallel, also tried to obtain the accreditation. This system is not integrated with De-Mail (there is no possibility of exchanging correspondence between systems) and similarly to the government system (E-Post..., 2013), it has not gained the expected popularity so far. An even worse situation was encountered by the Italian public post, whose PostaCertificat @ system was completely eliminated from the market by competitors after several years of operation (www.postacertificata.gov.it, 2015). The reason for this was the inability of the system to support e-communication of citizens with commercial companies. Providing e-communication exclusively to the state administration turned out to be extremely unprofitable for public mail in Italy.

By attempting to generalize the good experiences of the European countries under study, a set of desirable features can be proposed, which should characterized the model of providing government-certified e-communication. First of all, the state should define the expected quality standard for the provision of services of e-communication, certified by a dedicated governmental agency. The e-box supporting this communication should be set up and operated free of charge by private individuals. However, due to respect for civil liberties, the use of e-communication should not be obligatory for private individuals. It is, however, justifiable and necessary to oblige not only administration bodies but also commercial companies to use e-communication. Administrative units and commercial users should bear the costs of sending e-mail.

Persons who do not have the competence, ability or willingness to use certified e-communication must be guaranteed service in a traditional form. A comprehensive approach, therefore, requires providing physical contact points where non-e-communication citizens would be able to access paper versions of all types of official documents. The obvious candidate for an entity dealing with such service seems to be a public post which usually has the best network of distribution offices in every country. An equally important advantage of public postal

\footnotetext{
${ }^{1}$ Own studies based on interviews with the representatives of digital service regulators of the countries presented.
} 
services is the possibility of immediate substitution of e-letters with paper letters due to the fact that the company has a physical delivery structure. ${ }^{2}$

It should be pointed out that in such countries as the Czech Republic, France, Finland or Denmark, the government has entrusted the whole or a leading role in servicing certified e-communication to public posts, arguing that these are companies well-suited to this role. ${ }^{3}$ The experience of the public post was also emphasized, indicating that the change in communication technology does not change its essence and function.

It should be noted, however, that preference in this area of the public post is heavily burdened with the risk of politicization of this decision. The project of mass replacement of citizens' paper documents with their digital counterparts implemented by the state obviously must result in the loss by the public post of revenues from the delivery of registered letters. For example, the Polish regulator of the postal market estimates that in the case of the state enforcing the use of e-communication as the primary form of public information service by the state administration, the public post would lose up to 65 per cent registered letters in the years 2019-2023. In financial terms, it would mean a loss of almost PLN 2 billion in revenues. It is also estimated that the related social effects will include reducing the number of public post employees by up to $30 \%$. This reduction would especially apply to rural areas, condemning them to an even greater deepening of civilization distance in relation to urban centres (Duszczyk, 2018). A state that owns the public post in Poland, like in most EU countries, would certainly be interested in compensating the company for losses incurred. Therefore, the government could exert a nonsubstantive pressure to include the public post in the group of entities servicing certified e-communication, and may even grant it exclusivity in this area. On the other hand, it should be considered an important argument that the state should rationalize spending on digitization and benefit from the support of useful solutions within the enterprises it owns.

\section{Social barriers and digital threats to the dissemination of e-communication}

The use of e-communication is nowadays not only facilitation, but sometimes a necessary condition for full participation in social, cultural and professional life. As a result, some citizens remain, for various reasons, at the margin of social change resulting from the wide implementation of ICT, which leads to the emergence of the phenomenon called "Digital divide".

Private individuals most often use these e-services, whose partial transfer to virtual reality is relatively easy, i.e. those that save citizens time and money: e-mail, instant messengers, online use of magazines, searching for information about goods and services. Wherever human contact is needed - longer conversation or individual problems of a high degree of complexity - for example in medicine or administration, the development of e-services is slow. The preference for personal settlement of official matters, which is reported by $53 \%$ of Internet users in the UE, is an important factor affecting the low level of the use of e-government services (Jedlińska, 2018).

The functioning of the information society is based on the predispositions, qualifications and experiences of individual people. Contact with new ICT applications requires constant education from citizens and often faces resistance from them even in countries with highly developed information infrastructure. This is reflected in the

\footnotetext{
2 The service consisting in transforming electronic information into paper documents (or vice versa) and only in this form delivered to the recipient is referred to as hybrid mail.

${ }^{3}$ The information from websites of public posts of the countries presented.
} 
Eurostat statistical surveys. For example, in $2017,78 \%$ of Polish households declared their use of the Internet (average for the EU28 - 87\%). As a reason for not using the Internet, private individuals in Poland reported in the order: no need to use the Internet, lack of the ability to use e-services, limited trust in e-services, too high costs of IT equipment and Internet access. In terms of quality, the factors that affect the use of these e-services the most are age and education. Among people who have never used the Internet, the largest group are people aged 55-74 and the least educated (Eurostat, 2018).

As indicated, most people who do not use e-communication do not feel such a need, which in the vast majority of cases should be combined with a lack of knowledge about the benefits for users of this tool. The biggest challenge seems to be overcoming the mental barrier, getting citizens to use e-services to actively influence their lives and become full members of the information society.

However, one can not overlook the fact that there are many risks associated with the use of ICT for communication needs. For example, existing methods of e-document authentication are less and less sufficient protection. The strongest, as yet, security features were offered by cryptographic systems used, among others, in the implementation of the electronic signature. However, the ever-increasing computing power of modern computers definitely increases the chances of success of the brute-force attack by finding the cryptographic key used by checking all its possible values. With the development of information technologies and the time of their use, IT systems, therefore, require continuous improvement of security. The promising direction in this area seems to be the use of convenient, ever cheaper and increasingly reliable biometric identification techniques. Some reservations, however, arise from the related limitation of privacy and concerns about appropriate supervision over the use of collected data.

Also, insufficient knowledge of users causes incorrect configuration of devices and applications that facilitate computer crimes. Users often use weak, easy to remember (and therefore to break) passwords, and on private digital devices install many applications from unknown sources that may be infected with malware. In addition, the factors that make computer crime an attractive form of criminal activity is that information documentation, that in a traditional system would be stored in different places, is available remotely and practically from anywhere. ${ }^{4}$ The fundamental role should, therefore, be attributed to educating the public so that citizens could obtain the necessary digital competences. ${ }^{5}$

\section{Conclusions}

In the information society, information processing and communication using ICT is a significant economic, social and cultural value. The status of a "digital citizen" now is attributed to those who use e-communication effectively and regularly (Mossberger, Tolbert, McNeal, 2008). On the other hand, it is increasingly difficult for a citizen to fully function in the social space without using this tool. The state, therefore, has the task of providing citizens with efficient digital service, while ensuring the necessary level of e-communication security. Due to the importance of the issues handled in this way, the validity of the documents sent is usually very significant due to their substantive and legal content. Nowadays, e-communication systems are more and more protected, and there

${ }^{4}$ Verizon research results, collected in the "Data Breach Investigation Report" report show that hackers manage to hack into almost all of the attacked computers in the hands of private persons within one day (Verizon, 2016).

${ }^{5}$ Digital competence consists of many specific information, communication and content manipulation skills. The average share of people with over-basic digital skills for the entire EU is 31\%, while in Poland this value does not exceed $21 \%$ (Methodological..., 2007). 
are many solutions on the market that combine the latest security technologies, but the threat is not diminishing at all. As a result, in the digital environment, the economic rights of citizens are constantly being violated and their sensitive data is being intercepted.

\section{References}

Duszczyk, M. (2018). List polecony dotrze do nas w postaci e-maila. Retrieved from: https://www.rp.pl/Biznes/306139909-Listpolecony-dotrze--do-nas-w-postaci-e-maila.html.

E-Post vs. De-Mail: Deutsche Post steigt endgültig bei De-Mail aus (2013). Retrieved from: www.heise.de/newsticker/meldung/E-Postvs-De-Mail-Deutsche-Post-steigt-endgueltig-bei-De-Mail-aus-1840900.html.

European Commission (2010). A Digital Agenda for Europe. Brussels, 19.5.2010. COM (2010) 245 final.

https://digst.dk.

https://ec.europa.eu/eurostat/data/database.

https://e-estonia.com.

Jedlińska, R. (2018). Wykluczenie cyfrowe w Polsce na tle krajów Unii Europejskiej. Ekonomiczne Problemy Usług, 2 (131/2).

Methodological Manual for statistics on the Information. Part II. Household Survey (2007). European Commission. Retrieved from: https://circabc.europa.eu.

Mossberger, K., Tolbert, C.J, McNeal, R.S. (2008). Digital Citizenship: The Internet, Society, and Participation. Cambridge: MIT Press.

Regulation (EU) No 910/2014 of the European Parliament and of the Council of 23 July 2014 on electronic identification and trust services for electronic transactions in the internal market and repealing Directive 1999/93/EC.

Verizon (2016). 2016 Data Breach Investigations Report. Retrieved from: https://www.verizonenterprise.com/resources/reports/ rp_DBIR_2016_Report_en_xg.pdf.

www.postacertificata.gov.it.

Cite this article aS: Buko, J. (2018). Premises and conditions for the implementation of government-certified e-communication on the example of selected EU countries. European Journal of Service Management, 4 (28/1), 49-54. DOI: 10.18276/ejsm.2018.28/1-06. 